\title{
Anterior Chamber Migration of Intravitreal Dexamethasone Implant in an Eye with Scleral-fixated Intraocular Lens
}

\author{
Neha Goel, MS, DNB, MNAMS, FRCS (Glasg); Aanchal Mehta, DNB; Jyoti Batra, MS; Reena Choudhry, MD, \\ DOMS, DNB, FRCS (Glasg)
}

Department of Ophthalmology, ICARE Eye Hospital and Postgraduate Institute, Noida, Uttar Pradesh, India

J Ophthalmic Vis Res 2020; 15 (4): 581-583

\section{PRESENTATION}

A 60-year-old woman with diabetes and hypertension presented with a decreased vision OD to 6/18 N10 due to cystoid macular edema (CME) following vitrectomy for removal of the dislocated posterior chamber intraocular lens (PCIOL) and scleral-fixated intraocular lens (SFIOL) implantation performed five months before. Spectral domain optical coherence tomography (SD-OCT) showed a central foveal thickness (CFT) of $484 \mu \mathrm{m}$. Intravitreal ranibizumab (LUCENTIS ${ }^{\circledR}$; Genentech, Inc) was administered; however, the CFT increased to $533 \mu \mathrm{m}$ after one month. She received intravitreal dexamethasone (DEX) implant (Ozurdex ${ }^{\circledR}$, Allergan Inc.), which resulted in best corrected visual acuity (BCVA) improvement to 6/12 N10 and CFT reduction to $404 \mu \mathrm{m}$ within a month. Three months later, CFT increased again to $677 \mu \mathrm{m}$ and she received a second DEX implant. Seven weeks following the injection, she presented with pain, corneal haze, and intraocular pressure (IOP) of $38 \mathrm{mmHg}$. A week later, IOP decreased to $16 \mathrm{mmHg}$ on brimonidine tartrate $0.2 \%$ and timolol maleate $0.5 \% \mathrm{BD}$; however, the DEX implant was seen in the anterior chamber (Figure 1a). Complete pupillary dilatation in this

Correspondence to:

Neha Goel, MS, DNB, MNAMS, FRCS (Glasg). D-91, Anand Niketan, New Delhi 110021, India.

E-mail: nehadoc@hotmail.com

Received: 24-10-2018Ａccepted: 29-07-2019

\section{Access this article online}

Website: https://knepublishing.com/index.php/JOVR

DOI: $10.18502 /$ jovr.v15i4.7798 vitrectomized eye allowed the implant to migrate forward through the gap between the IOL edge and the pupil (Figure 1b).

There was no corneal edema and BCVA was maintained at 6/12 N10. Specular microscopy showed an endothelial count (EC) of 1144 cells $/ \mathrm{mm}^{2}$ (Figure 1c). SD-OCT revealed a CFT of $365 \mu \mathrm{m}$ (Figure 1d). A trial of wide pupillary dilatation with supine position failed to reposition the implant into the vitreous cavity. Pros and cons of implant removal were discussed and patient opted for weekly follow-up. Corneal clarity was maintained, EC was 1106, 1181, 1193, and 1205 cells $/ \mathrm{mm}^{2}$ at each weekly visit, respectively, and IOP remained $<20 \mathrm{mmHg}$ without treatment. Within a month, the implant disappeared from the anterior chamber, although the CFT increased again to $711 \mu \mathrm{m}$. Due to the recent anterior migration of DEX implant, three monthly doses of intravitreal ranibizumab were administered. Suboptimal visual and anatomical results led us to inject DEX implant again, with care taken not to dilate the pupil fully at any time. She underwent four intravitreal DEX implants over the following year; BCVA remained stable at $6 / 12$ N8 with a clear cornea, IOP $<20 \mathrm{mmHg}$ in the absence of therapy, no recurrence of CME, and no anterior migration of the implant.

This is an open access journal, and articles are distributed under the terms of the Creative Commons Attribution-NonCommercial-ShareAlike 4.0 License, which allows others to remix, tweak, and build upon the work non-commercially, as long as appropriate credit is given and the new creations are licensed under the identical terms.

How to cite this article: Goel N, Mehta A, Batra J, Choudhry R. Anterior Chamber Migration of Intravitreal Dexamethasone Implant in an Eye with Scleral-fixated Intraocular Lens. J Ophthalmic Vis Res 2020;15:581-583. 


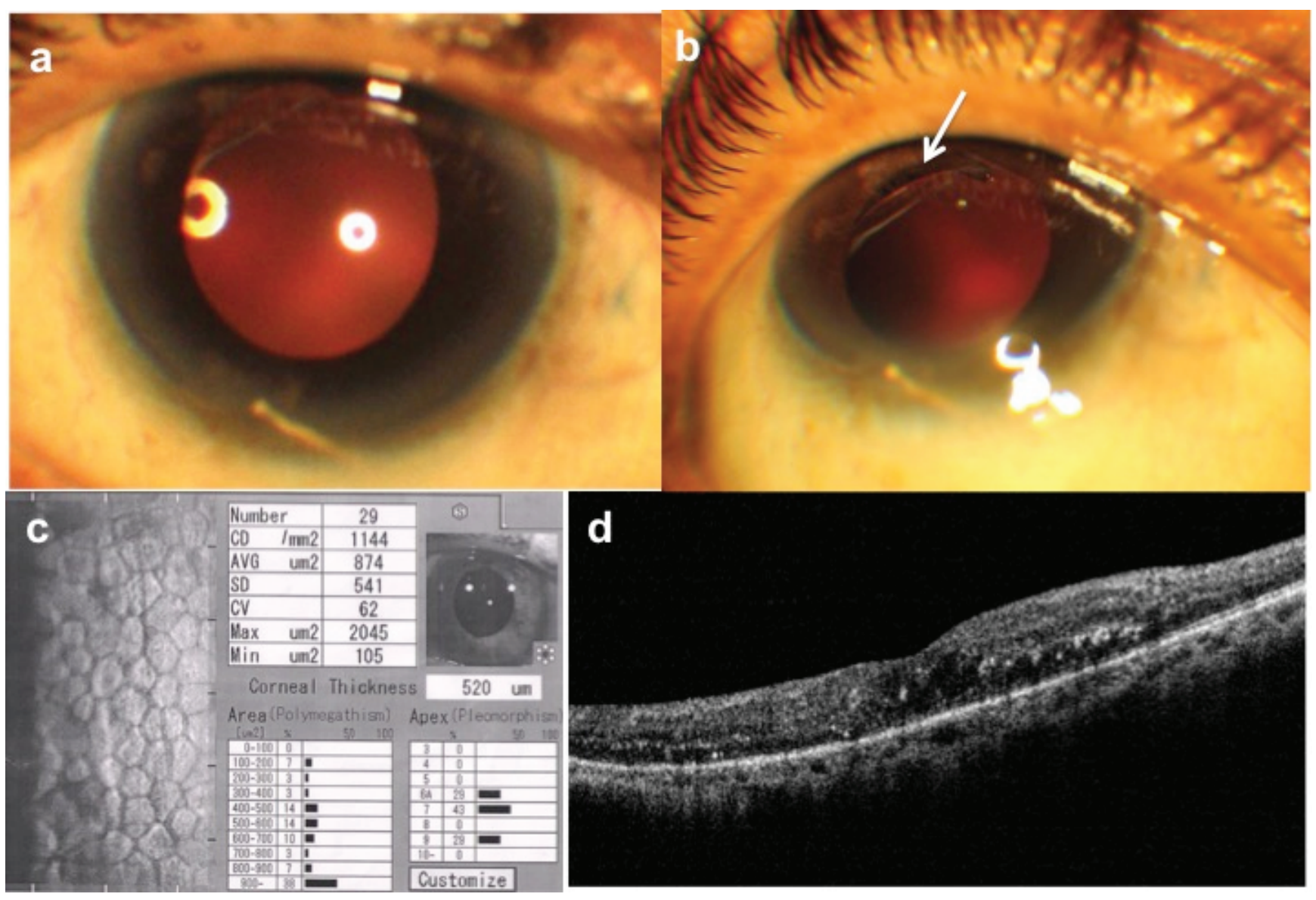

Figure 1. (a) Clinical photograph of the right eye showing a clear cornea, scleral-fixated posterior chamber intraocular lens (SFIOL) in situ, and an intravitreally administered dexamethasone (DEX) implant lying inferiorly in the anterior chamber. (b) A gap between the IOL edge and pupil margin could be seen in upgaze (white arrow). (c) Endothelial count of the right eye performed on the same day. (d) Spectral domain optical coherence tomography (SD-OCT) showing mild macular edema and hard exudates.

\section{DISCUSSION}

Intravitreal DEX implant is a safe and effective therapeutic option for post-surgical macular edema. ${ }^{[1]}$ Anterior chamber migration of the implant is a potential, though uncommon complication, in eyes with a compromised lens capsule, prior to vitrectomy and/or iris defects. ${ }^{[2,3]}$ Very few cases of migration in eyes with an SFIOL have been reported, ${ }^{[2,4,5]}$ as has occurred in this case, reinforcing that the presence of an $\mathrm{IOL}$ alone does not prevent the implant migration when the posterior capsule is not intact. As a precaution to minimize recurrent migration, the pupil size was kept reduced enough to cover the edge of the optic.

Corneal endothelial decompensation is the most serious complication resulting from the migration of implant into the anterior chamber. ${ }^{[1,4]}$ Early migration (within three weeks of injection) could result in higher incidence of corneal edema as higher rigidity of the implant in the first weeks could cause greater mechanical endothelial trauma. ${ }^{[2]}$ This would explain why our patient did not develop corneal edema and could avoid the additional procedure of immediate repositioning or removing the implant, which reduces the likelihood of permanent corneal edema. ${ }^{[2,3]}$

While vitrectomized eyes without an intact lens capsule are at risk for anterior migration of a DEX implant, this subset of patients may also benefit most from having a DEX implant administered for post-surgical macular edema. A regular postinjection follow-up can recognize and manage this rare, though potentially vision threatening, complication at the earliest. An individualized approach is recommended that takes into account the potential anterior segment complications as well as loss of drug effectiveness. A single episode of anterior chamber migration of the DEX implant should not be considered as a contraindication for further injections if warranted. 


\section{Financial Support and Sponsorship}

Nil.

\section{Conflicts of Interest}

There are no conflicts of interest.

\section{REFERENCES}

1. Bellocq D, Pierre-Kahn V, Matonti F, Burillon C, Voirin N, Dot $C$, et al. Effectiveness and safety of dexamethasone implants for postsurgical macular oedema including IrvineGass syndrome: the EPISODIC-2 study. $\mathrm{Br} \mathrm{J}$ Ophthalmol 2017;101:333-341.
2. Khurana RN, Appa SN, McCannel CA, Elman MJ, Wittenberg SE, Parks DJ, et al. Dexamethasone implant anterior chamber migration: risk factors, complications, and management strategies. Ophthalmology 2014;121:6771.

3. Rahimy E, Khurana RN. Anterior segment migration of dexamethasone implant: risk factors, complications, and management. Curr Opin Ophthalmol 2017;28:246-251.

4. Marchese V, Piscitello S, Vaccaro C, Giunchiglia G. Management of intravitreal implant migration into the anterior chamber in a patient with a posterior chamber intraocular lens. JCRS Online Case Rep 2014;2:e31-e34.

5. Pacella F, Agostinelli E, Carlesimo SC, Nebbioso M, Secondi R, Forastiere M, et al. Management of anterior chamber dislocation of a dexamethasone intravitreal implant: a case report. J Med Case Rep 2016;10:282. 